\title{
VCAM-1 serum levels are associated with arthropathy in hereditary haemochromatosis
}

\author{
Valerie Nell-Duxneuner, ${ }^{1}$ Roland Axmann, ${ }^{1}$ Emma Husar-Memmer, ${ }^{1}$ Tomáš Dallos, ${ }^{2,3}$ \\ Christian Datz, ${ }^{4}$ Andreas Stadlmayr, ${ }^{4}$ Elmar Aigner, ${ }^{4,5}$ Matthias Englbrecht, ${ }^{3}$ \\ Georg Schett, ${ }^{3}$ Jochen Zwerina ${ }^{1,3}$
}

\begin{abstract}
Handling editor Tore K Kvien
- Additional material is

published online only. To view please visit the journal online (http://dx.doi.org/10.1136/ annrheumdis-2012-202800).

${ }^{1} 1$ st Medical Department, Ludwig Boltzmann Institute of Osteology at the Hanusch Hospital of WGKK and AUVA Trauma Centre Meidling, Hanusch Hospital, Vienna, Austria

${ }^{2}$ 2nd Department of Pediatrics, Comenius University Bratislava, Bratislava, Slovak Republic ${ }^{3}$ Department of Internal Medicine 3, Institute for Clinical Immunology, University of Erlangen-Nurnberg, Nürnberg, Germany ${ }^{4}$ Department of Internal Medicine, Hospital Oberndorf, Oberndorf, Austria

${ }^{5} 1$ st Medical Department, Paracelsus Medical University Salzburg, Salzburg, Austria
\end{abstract}

\section{Correspondence to}

Dr Jochen Zwerina,

1st Medical Department Ludwig Boltzmann Institute of Osteology at the Hanusch Hospital of WGKK and AUVA Trauma Centre Meidling, Hanusch Hospital,

Vienna 1140, Austria; jochen.zwerina@osteologie.at

Accepted 1 April 2013 Published Online First 18 April 2013

\footnotetext{
To cite: Nell-Duxneuner $\mathrm{V}$, Axmann R, Husar-

Memmer $\mathrm{E}$, et al. Ann Rheum Dis 2013;72. 2006-2010.
}

\section{ABSTRACT}

Objectives The aim of this study was to assess the role of vascular adhesion molecule 1 (VCAM-1) in patients with hereditary haemochromatosis $(\mathrm{HH})$ with or without arthropathy.

Methods Sera from a large cross-sectional cohort of unselected HH patients ( $n=147$ ) were obtained and compared to an age-matched and sex-matched control group. Serum levels of VCAM-1 were measured by ELISA and were correlated with clinical measures.

Results VCAM-1 serum levels were elevated in $\mathrm{HH}$ patients as compared to matched controls (mean $913 \pm 456$ vs $654 \pm 451 \mathrm{ng} / \mathrm{ml}, \mathrm{p}<0.0001)$. Within the $\mathrm{HH}$ patient group, VCAM-1 levels were much higher in patients with arthropathy and joint replacement surgery. VCAM-1 levels correlated well with radiographic measures of $\mathrm{HH}$ arthropathy $(r=0.36, p<0.0001)$. Multivariate regression analysis confirmed a highly significant association of VCAM-1 serum levels and the presence of $\mathrm{HH}$ arthropathy, independent from diabetes, body mass index and age.

Conclusions VCAM-1 serum levels emerge as a biomarker for haemochromatosis arthropathy.

\section{INTRODUCTION}

Hereditary haemochromatosis $(\mathrm{HH})$ is the most frequent autosomal-recessive disorder in Caucasians usually caused by a homozygous C282Y mutation in the HFE gene. ${ }^{1}$ This mutation leads to an abnormal increased iron absorption in the gut. Typically patients developing symptoms of iron overload are between 30 and 50 years of age and predominantly men. The classical triad of liver cirrhosis, diabetes and hyperpigmentation is however rare in clinical practice nowadays. In fact, the most frequent symptoms leading to diagnosis are currently arthralgias and clinically silent elevated liver enzymes. $^{2}$

In 1964, Schumacher recognised arthritis as a leading clinical symptom in $\mathrm{HH}$ patients. ${ }^{3}$ Recent evidence suggests that approximately $30-50 \%$ of $\mathrm{HH}$ patients develop an associated arthropathy. The typical location of arthritis is the second and third metacarpophalangeal (MCP) joint, but hip, knee and ankle joints can also be affected. ${ }^{4}$ Misdiagnosis as rheumatoid arthritis or idiopathic osteoarthritis (OA) is not uncommon. About one-third of $\mathrm{HH}$ patients show radiographic signs of chondrocalcinosis, although pseudogout is a rather uncommon clinical presentation. In affected
MCP joints, conventional radiographs show hooklike osteophytes, cysts and sometimes even erosions. $^{5}$

Little is known about risk factors for development of $\mathrm{HH}$ arthropathy nor do we fully understand the pathophysiology. Apart from the degree of iron overload itself, only women's sex and age are associated with joint involvement in $\mathrm{HH}^{6}{ }^{6}$ Thus, we are currently not sufficiently able to prevent or even predict arthropathy in $\mathrm{HH}$ patients. Vascular adhesion molecule 1 (VCAM-1) has recently been implicated as a risk factor for degenerative arthritis. While the exact pathophysiological role of VCAM-1 is unclear, high serum levels of VCAM-1 are strongly associated with the development of idiopathic OA. ${ }^{8-10}$ In this study, we thus investigated VCAM-1 serum levels in a large cohort of $\mathrm{HH}$ patients and correlated these with the clinical manifestations including arthropathy.

\section{METHODS}

Details of inclusion criteria, clinical assessment, radiographic scoring, VCAM-1 measurements and statistical analyses are given in online supplementary information.

\section{RESULTS}

\section{Demographics}

Clinical details for the $\mathrm{HH}$ and control group are given in table 1 . Briefly, we included $147 \mathrm{HH}$ patients and 147 age- and sex-matched controls. ${ }^{11}$

\section{VCAM-1 serum levels in matched controls and correlations to possible confounders}

VCAM-1 levels in the control group were not significantly correlated with age $(\mathrm{r}=0.119, \mathrm{p}=0.151)$, diabetes $(r=0.03, p=0.790)$ or high blood pressure $(\mathrm{r}=0.097, \mathrm{p}=0.243)$ and only very weakly correlated with body mass index (BMI) $(r=0.169$, $\mathrm{p}=0.043$ ). There was no significant correlation between VCAM-1 levels and the number of smokers $(r=0.138, p=0.130)$ nor their pack years $(\mathrm{r}=0.120, \mathrm{p}=0.191)$.

\section{VCAM-1 serum levels in HH patients with or without arthropathy}

We found significantly elevated VCAM-1 serum levels in $\mathrm{HH}$ patients (mean level $913 \pm 456 \mathrm{ng} / \mathrm{ml}$ ) as compared to matched controls (mean level $654 \pm 451 \mathrm{ng} / \mathrm{ml}, \mathrm{p}<0.0001)$. Interestingly, VCAM-1 levels were higher in $\mathrm{HH}$ patients with arthropathy 
Table 1 Demographics of patients with haemochromatosis and age-matched and sex-matched controls

\begin{tabular}{|c|c|c|c|}
\hline & Hereditary haemochromatosis $n=147$ & Control group $n=147$ & $\mathrm{p}$ Value \\
\hline Men/women (\%) & $67 / 33$ & $67 / 33$ & \\
\hline Age in years, mean (SD) & $56(12)$ & $56(12)$ & 0.941 (ns) \\
\hline BMI, mean (SD) & $26.3(3.6)$ & $25.2(4.4)$ & 0.002 \\
\hline Diabetes, n (\%) & $18(12)$ & $11(8)$ & 0.171 (ns) \\
\hline C282Y homozygous mutation, n (\%) & $147(100)$ & NA & \\
\hline Highest serum ferritin level (ng/ml), mean (SD) & $2267.5(2282.2)$ & $155.5(137.8)$ & $<0.0001$ \\
\hline Elevated liver enzymes, $n(\%)$ & $60(41.7)$ & NA & \\
\hline Advanced liver disease, $\mathrm{n}(\%)$ & $29(19.7)$ & NA & \\
\hline CRP, mg/l, mean (SD) & $3.5(5.5)$ & $0.3(1.0)$ & $<0.0001$ \\
\hline VCAM-1, ng/ml, mean (SD) & $913(456)$ & $654(451)$ & $<0.0001$ \\
\hline MCP 2/3 radiological score, mean (SD) & $7.1(6.7)$ & NA & \\
\hline Presence of arthropathy, n (\%) & $81(55)$ & NA & \\
\hline MCP $2 / 3$ bony swollen, mean (SD) & $1.8(1.8)$ & NA & \\
\hline Treated patients, n (\%) & $140(95)$ & NA & \\
\hline Joint replacement surgery due to osteoarthritis, $n(\%)$ & $23(16)$ & $0(0)$ & $<0.0001$ \\
\hline
\end{tabular}

$(\mathrm{n}=81, \quad 55.1 \%$; mean $1049 \pm 527 \mathrm{ng} / \mathrm{ml})$ as compared to $\mathrm{HH}$ patients without arthropathy $(\mathrm{n}=66,44.9 \%$; mean $746 \pm 272 \mathrm{ng} / \mathrm{ml}, \mathrm{p}<0.0001$; figure $1 \mathrm{~A})$. We also compared patients with and without arthropathy to the matched controls: VCAM-1 levels were significantly lower in controls than in $\mathrm{HH}$ patients with and without arthropathy ( $\mathrm{p}<0.0001$ for both comparisons).

We analysed VCAM-1 levels in those patients who have had a joint replacement surgery of the knee or hip. VCAM-1 was once more significantly higher in patients who had received joint replacement surgery compared to those $\mathrm{HH}$ patients without joint replacement (mean $985 \pm 320$ vs $900 \pm 477 \mathrm{ng} / \mathrm{ml}$, $\mathrm{p}=0.028$; figure $1 \mathrm{~B}$ ).

The relationship between VCAM-1 and $\mathrm{HH}$ arthropathy was further investigated using the radiographic haemochromatosis arthropathy score. ${ }^{12}$ There was a moderate but highly significant correlation between VCAM-1 levels and the MCP 2/3 x-ray score $(\mathrm{r}=0.36, \mathrm{p}<0.0001$; figure 2$)$.

\section{The independent effect of increased VCAM-1 in haemochromatosis arthropathy after controlling for possible confounders}

The primary question was, if VCAM-1 was independently associated with arthropathy in our patient cohort after correcting for possible confounders. We chose a regression model and defined the previously described radiographic scoring method specifically developed and validated in patients with $\mathrm{HH}$ arthropathy as outcome variable. The model allowed investigation of VCAM-1 as primary measure while controlling for age, diabetes and BMI.

Age, diabetes and BMI explained 24\% of the variance in the $\mathrm{x}$-ray score. After introduction of VCAM-1 into the model, the total variance explained by the model increased to $28.2 \%$ $(\mathrm{F}(4,142)=13.94, \mathrm{p}<0.0001)$. VCAM-1 therefore added statistically significant input to the variance in arthropathy, even after controlling for age, diabetes and BMI $\left(\mathrm{R}^{2}=0.041, \mathrm{~F}\right.$ change $(1,14)=8.20, p=0.005)$. In the final model, only VCAM-1 $(\beta=0.22, p=0.005)$ and age $(\beta=0.37, p<0.0001)$ were significantly associated with the development of arthropathy.

Since our analyses suggested a close correlation between VCAM-1 and arthropathy on the one hand and between age and arthropathy on the other hand, we decided to perform further analyses. We explored the relationship between VCAM-1 and arthropathy while controlling for age using partial correlation. There was a strong correlation between VCAM-1 and the x-ray score, even after controlling for age, $\mathrm{r}=0.27$, $p<0.0001$. Further inspections of this model suggested that the strength of the relationship between VCAM-1 and arthropathy was largely independent from age (zero-order correlation; $\mathrm{r}=0.36)$.

\section{Correlation of VCAM-1 with arthropathy is largely independent of liver disease in $\mathrm{HH}$ patients}

VCAM-1 serum levels were higher in patients with elevated liver enzymes at diagnosis (mean $1046 \pm 521 \mathrm{vs} 827 \pm 388 \mathrm{ng} / \mathrm{ml}$, $\mathrm{p}=0.003$ ) and advanced liver disease (mean $1303 \pm 737$ vs $817 \pm 287 \mathrm{ng} / \mathrm{ml}, \mathrm{p}<0.0001)$. Again, we applied partial correlation in order to explore the relationship between VCAM-1 and arthropathy while controlling for advanced liver disease. There was a strong correlation between VCAM-1 and the x-ray score, even after controlling for advanced liver disease $(r=0.222$, $\mathrm{p}=0.008)$.

\section{DISCUSSION}

Joint pain and fatigue are the most common presenting symptoms in $\mathrm{HH}$ nowadays and many patients also show biochemical evidence of liver injury. ${ }^{2}$ There is no clear evidence why some patients develop arthropathy and others do not. At the same time, therapeutic phlebotomy prevents liver cirrhosis but does not affect arthropathy. ${ }^{13}$ Contrary to all other clinical manifestations, arthropathy can even develop after initiation of phlebotomy treatment. Only women's age and sex seem to predict the presence of articular damage, but we know that traditional risk factors such as diabetes and BMI are not associated with $\mathrm{HH}$ arthropathy. ${ }^{4}$

The causes of haemochromatosis arthropathy are currently enigmatic. Iron deposition is found in haemochromatosis joints but this is an unspecific phenomenon. ${ }^{6} 714$ One significant finding is premature chrondrocalcinosis of wrists and knee joints, although pseudogout attacks are uncommon in clinical practice. Nevertheless, cartilage calcification may play a role in degenerative arthritis in HH. Histologically, mostly mild synovitis is 

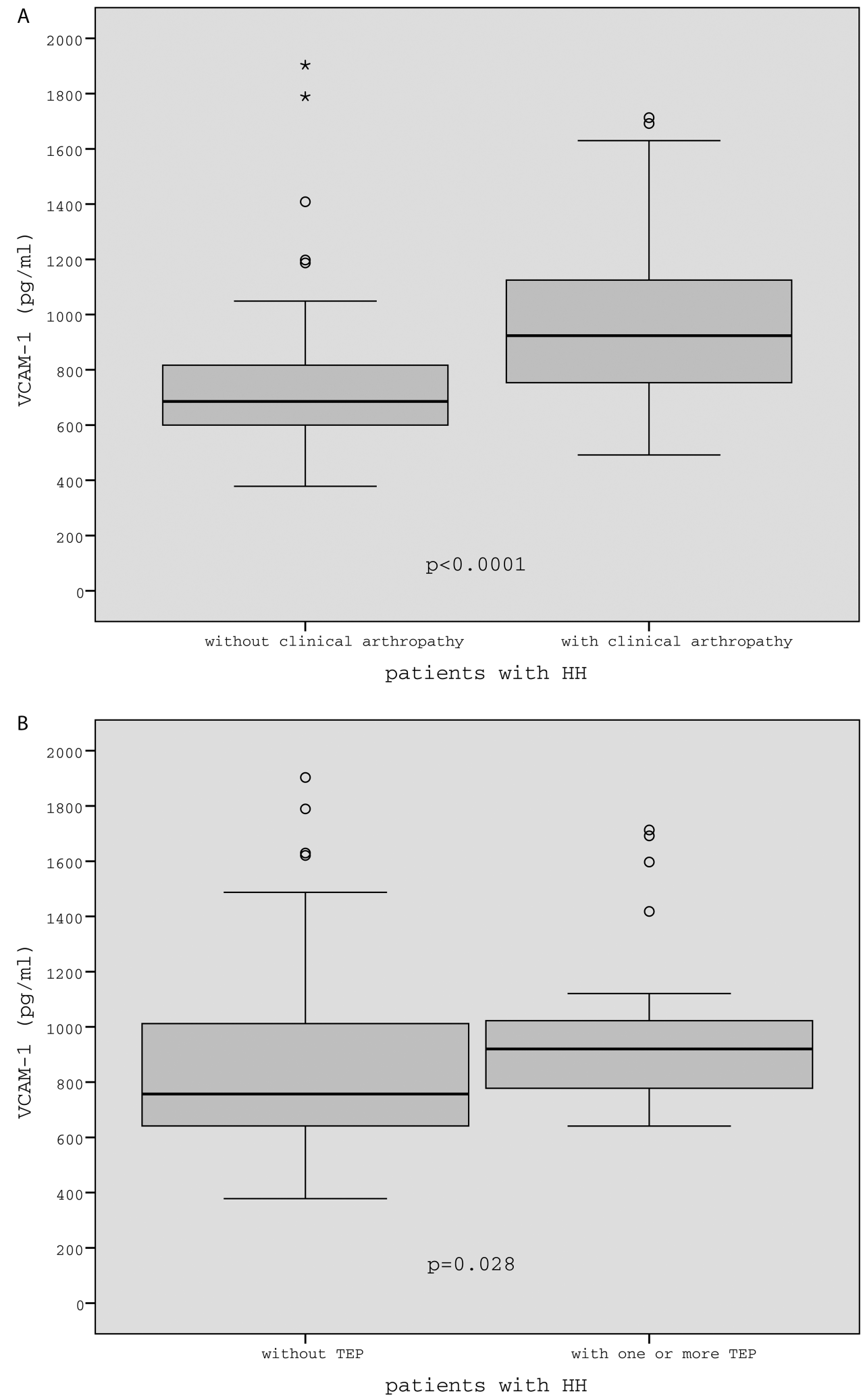

Figure 1 (A) Vascular adhesion molecule 1 (VCAM-1) levels of hereditary haemochromatosis (HH) patients with and without clinical arthropathy were compared, demonstrating significantly higher VCAM-1 levels for patients with arthropathy. (B) VCAM-1 levels depending on history of joint replacement surgery in HH patients. Patients who had joint replacement had significantly higher levels of VCAM-1.

observed similar to idiopathic OA. The only distinguishing feature is a more prominent infiltration of neutrophils. ${ }^{15}$

VCAM-1 is expressed on the endothelium of blood vessels facilitating leukocyte adhesion and recruitment into inflamed tissues. ${ }^{16}$ In degenerative and inflammatory arthritis, VCAM-1 is locally expressed on endothelial cells, macrophages, fibroblasts and chondrocytes. ${ }^{17}$ Pro-inflammatory mediators such as interleukin 1 can increase VCAM-1 expression. ${ }^{18}$ Furthermore, hyaluron released during articular cartilage damage also induces VCAM-1 production. ${ }^{19}$ Interaction of chondrocytes and immune cells may 


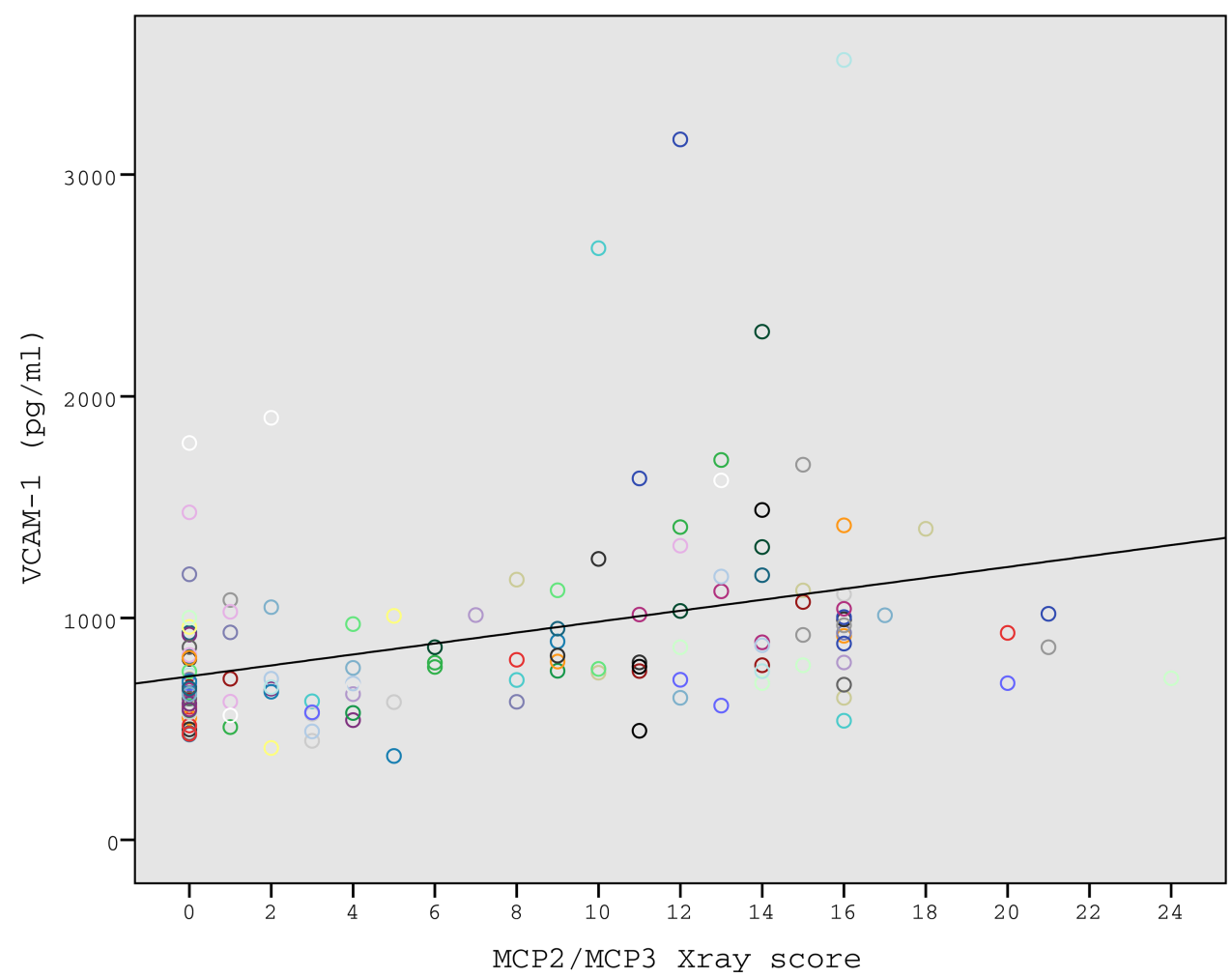

Figure 2 Correlation between vascular adhesion molecule 1 (VCAM-1) levels and MCP 2/3 x-ray score in hereditary haemochromatosis patients showing a highly significant correlation $(r=0.36, p<0.0001)$. MCP, metacarpophalangeal. Access the article online to view this figure in colour.

also be VCAM-1 dependent. ${ }^{17}$ Neutralisation of VCAM-1 reduces joint inflammation in murine models of arthritis. ${ }^{20}$ Thus, VCAM-1 is a possible mediator of articular damage.

In a recent study, we found elevated VCAM-1 but none of the other leukocyte adhesion molecule serum levels were independently associated with the development of knee and hip OA. ${ }^{13}$ Although this study needs replication, VCAM-1 may emerge as one of few predictors of large joint OA apart from known ones such as women's age, sex and overweight. Elevated VCAM-1 levels have also been linked to the presence of hand OA in a cohort of Chuvashian patients. ${ }^{8}$ The pathophysiological link between VCAM-1 and degenerative arthritis is however currently unknown.

Our cohort of $\mathrm{HH}$ patients reflects the current clinical situation. Two-thirds of patients were men, 55\% presented with arthropathy and $16 \%$ already had joint replacement. We found significantly elevated serum VCAM-1 levels in $\mathrm{HH}$ patients as compared to age- and sex-matched controls. Interestingly, VCAM-1 levels correlated well with radiographic severity. Furthermore, VCAM-1 levels were also elevated significantly in the most severely affected $\mathrm{HH}$ patients having undergone joint replacement surgery. Multivariate analysis revealed the highly significant independent association of VCAM-1 levels with $\mathrm{HH}$ arthropathy after controlling for diabetes, BMI and age. Furthermore, in our analysis, VCAM-1 levels were partially independent of the presence of advanced liver disease, even though severity of HH itself might explain elevated VCAM-1 levels.

Thus, VCAM-1 may indeed link chronic iron overload and arthropathy in $\mathrm{HH}$ patients although causal relationships are yet unclear. We also do not know whether VCAM-1 levels are elevated in untreated newly diagnosed $\mathrm{HH}$ patients and more importantly whether VCAM-1 levels could predict development of $\mathrm{HH}$ arthropathy.
In summary, we have shown an independent and highly significant association of VCAM-1 levels and $\mathrm{HH}$ arthropathy. Further prospective studies are needed to validate our findings of a new biomarker in $\mathrm{HH}$ patients.

Acknowledgements We thank Enijad Sahinbegovic (Department of Internal Medicine 3, University of Erlangen-Nuremberg, Erlangen, Germany), Gernot Keyßer (Department of Internal Medicine I, Martin-Luther-University Halle-Wittenberg, Halle/Saale, Germany), Ulrich Stölzel (Department of Medicine 2, Hospital Chemnitz, Chemnitz, Germany), Thomas Karger (Rheumapraxis Cologne, Germany), Martin Farkas (Department of Internal Medicine 1, Hospital Wiener Neustadt, Austria), Thomas Karonitsch, Josef Smolen and Maximilian Schöniger-Hekele (all Department of Internal Medicine 3, Medical University of Vienna, Austria) for recruiting haemochromatosis patients.

Contributors All authors contributed substantially in conception and design, or analysis and interpretation of data, or drafting the article or revising it critically for important intellectual content or finally approved the version to be published.

Funding This study was supported by the German Society of Rheumatology (Start Up grant to J.Z.) and the Austrian Science Fund (FWF): KLI123. Tomáš Dallos was supported by a Pfizer Articulum Fellowship.

Competing interests None.

Patient consent Obtained.

Ethics approval Ethic Committees.

Provenance and peer review Not commissioned; externally peer reviewed.

\section{REFERENCES}

1 Datz C, Lalloz MR, Vogel W, et al. Predominance of the HLA-H Cys282Tyr mutation in Austrian patients with genetic hemochromatosis. J Hepatol 1997;27:773-9.

2 Allen KJ, Gurrin LC, Constantine CC, et al. Iron-overload-related disease in HFE hereditary hemochromatosis. N Engl J Med 2008;358:221-30.

3 Schumacher HR Jr. Hemochromatosis and arthritis. Arthritis Rheum 1964;7:41-50.

4 Sahinbegovic E, Dallos T, Aigner E, et al. Hereditary hemochromatosis as a risk factor for joint replacement surgery. Am J Med 2010;123:659-62.

5 Jäger HJ, Mehring U, Götz GF, et al. Radiological features of the visceral and skeletal involvement of hemochromatosis. Eur Radiol 1997;7:1199-206. 


\section{Clinical and epidemiological research}

6 Sahinbegovic E, Dallos T, Aigner E, et al. Musculoskeletal disease burden of hereditary hemochromatosis. Arthritis Rheum 2010;62:3792-8.

7 Valenti L, Fracanzani AL, Rossi V, et al. The hand arthropathy of hereditary hemochromatosis is strongly associated with iron overload. I Rheumatol 2008:35:153-8.

8 Kalichman L, Pantsulaia I, Kobyliansky E. Association between vascular cell adhesion molecule 1 and radiographic hand osteoarthritis. Clin Exp Rheumatol 2011;29:544-6.

9 Schett G, Kiechl S, Bonora E, et al. Vascular cell adhesion molecule 1 as a predictor of severe osteoarthritis of the hip and knee joints. Arthritis Rheum 2009:60:2381-9.

10 Grogan SP, Miyaki S, Asahara H, et al. Mesenchymal progenitor cell markers in human articular cartilage: normal distribution and changes in osteoarthritis. Arthritis Res Ther 2009;11:R85

11 Stadlmayr A, Aigner E, Steger B, et al. Nonalcoholic fatty liver disease: an independent risk factor for colorectal neoplasia. J Intern Med 2011;270:41-9.

12 Dallos T, Sahinbegovic E, Aigner E, et al. Validation of a radiographic scoring system for hemochromatosis. Ann Rheum Dis 2010;69:2145-51.

13 McDonnell SM, Preston BL, Jewell SA, et al. A survey of 2,851 patients with hemochromatosis: symptoms and response to treatment. Am J Med 1999;106:619-24.
14 Bennett RM, Williams ED, Lewis SM, et al. Synovial iron deposition in rheumatoid arthritis. Arthritis Rheum 1973;16:298-304.

15 Heiland GR, Aigner E, Dallos T, et al. Synovial immunopathology in haemochromatosis arthropathy. Ann Rheum Dis 2010;69:1214-19.

16 Marazuela M, Postigo AA, Acevedo A, et al. Adhesion molecules from the LFA-1/ICAM-1,3 and VLA-4/VCAM-1 pathways on T lymphocytes and vascular endothelium in Graves' and Hashimoto's thyroid glands. Eur I Immunol 1994;24:2483-90.

17 Kienzle G, von Kempis J. Vascular cell adhesion molecule 1 (CD106) on primary human articular chondrocytes: functional regulation of expression by cytokines and comparison with intercellular adhesion molecule 1 (CD54) and very late activation antigen 2. Arthritis Rheum 1998;41:1296-305.

18 Osborn L, Hession C, Tizard R, et al. Direct expression cloning of vascular cell adhesion molecule 1, a cytokine-induced endothelial protein that binds to lymphocytes. Cell 1989;59:1203-11.

19 Fujii K, Tanaka Y, Hubscher S, et al. Cross-linking of CD44 on rheumatoid synovial cells up-regulates VCAM-1. J Immunol 1999;162:2391-8.

20 Carter RA, Campbell IK, O'Donnel KL, et al. Vascular cell adhesion molecule-1 (VCAM-1) blockade in collagen-induced arthritis reduces joint involvement and alters B cell trafficking. Clin Exp Immunol 2002;128:44-51. 


\section{VCAM-1 serum levels are associated with arthropathy in hereditary haemochromatosis}

Valerie Nell-Duxneuner, Roland Axmann, Emma Husar-Memmer, Tomás Dallos, Christian Datz, Andreas Stadlmayr, Elmar Aigner, Matthias Englbrecht, Georg Schett and Jochen Zwerina

Ann Rheum Dis 2013 72: 2006-2010 originally published online April 18, 2013

doi: 10.1136/annrheumdis-2012-202800

Updated information and services can be found at:

http://ard.bmj.com/content/72/12/2006

These include:

Supplementary Material

References

Email alerting service
Supplementary material can be found at:

http://ard.bmj.com/content/suppl/2013/04/16/annrheumdis-2012-2028 00.DC1.html

This article cites 20 articles, 4 of which you can access for free at: http://ard.bmj.com/content/72/12/2006\#BIBL

Receive free email alerts when new articles cite this article. Sign up in the box at the top right corner of the online article.

Topic Articles on similar topics can be found in the following collections

Collections Immunology (including allergy) (5144)

\section{Notes}

To request permissions go to:

http://group.bmj.com/group/rights-licensing/permissions

To order reprints go to:

http://journals.bmj.com/cgi/reprintform

To subscribe to BMJ go to:

http://group.bmj.com/subscribe/ 